\title{
Plant traits correlated with generation time directly affect inbreeding depression and mating system and indirectly genetic structure
} Jérôme Duminil*1,2, Olivier J Hardy ${ }^{1}$ and Rémy J Petit ${ }^{3,4}$

\begin{abstract}
Address: ${ }^{1}$ Université Libre de Bruxelles, Faculté des Sciences, Service Evolution Biologique et Ecologie, CP 160/12, 50 Av. F. Roosevelt, 1050 Bruxelles, Belgium, ${ }^{2}$ Faculté Universitaire des Sciences Agronomiques de Gembloux, Laboratoire d'écologie, 2 Passage des Déportés 5030 Gembloux, Belgium, ${ }^{3}$ INRA, UMR 1202 Biodiversity, Genes and Communities, F-33610 Cestas, France and ${ }^{4}$ Université de Bordeaux, UMR 1202 Biodiversity, Genes and Communities, F-33610 Cestas, France

Email: Jérôme Duminil* - jduminil@ulb.ac.be; Olivier J Hardy - ohardy@ulb.ac.be; Rémy J Petit - petit@pierroton.inra.fr

* Corresponding author
\end{abstract}

Published: 27 July 2009

BMC Evolutionary Biology 2009, 9:177 doi:10.1186/147|-2/48-9-177

This article is available from: http://www.biomedcentral.com//47I-2/48/9//77

(c) 2009 Duminil et al; licensee BioMed Central Ltd.

This is an Open Access article distributed under the terms of the Creative Commons Attribution License (http://creativecommons.org/licenses/by/2.0), which permits unrestricted use, distribution, and reproduction in any medium, provided the original work is properly cited.
Received: 31 March 2009

Accepted: 27 July 2009

\begin{abstract}
Background: Understanding the mechanisms that control species genetic structure has always been a major objective in evolutionary studies. The association between genetic structure and species attributes has received special attention. As species attributes are highly taxonomically constrained, phylogenetically controlled methods are necessary to infer causal relationships. In plants, a previous study controlling for phylogenetic signal has demonstrated that Wright's $F_{S T}$, a measure of genetic differentiation among populations, is best predicted by the mating system (outcrossing, mixed-mating or selfing) and that plant traits such as perenniality and growth form have only an indirect influence on $F_{\mathrm{ST}}$ via their association with the mating system. The objective of this study is to further outline the determinants of plant genetic structure by distinguishing the effects of mating system on gene flow and on genetic drift. The association of biparental inbreeding and inbreeding depression with population genetic structure, mating system and plant traits are also investigated.
\end{abstract}

Results: Based on data from 263 plant species for which estimates of $F_{\mathrm{ST}}$, inbreeding $\left(F_{\mathrm{IS}}\right)$ and outcrossing rate $\left(t_{\mathrm{m}}\right)$ are available, we confirm that mating system is the main influencing factor of $F_{\mathrm{ST}}$. Moreover, using an alternative measure of $F_{\mathrm{ST}}$ unaffected by the impact of inbreeding on effective population size, we show that the influence of $t_{\mathrm{m}}$ on $F_{\mathrm{ST}}$ is due to its impact on gene flow (reduced pollen flow under selfing) and on genetic drift (higher drift under selfing due to inbreeding). Plant traits, in particular perenniality, influence $F_{\mathrm{ST}}$ mostly via their effect on the mating system but also via their association with the magnitude of selection against inbred individuals: the mean inbreeding depression increases from short-lived herbaceous to long-lived herbaceous and then to woody species. The influence of perenniality on mating system does not seem to be related to differences in stature, as proposed earlier, but rather to differences in generation time.

Conclusion: Plant traits correlated with generation time affect both inbreeding depression and mating system. These in turn modify genetic drift and gene flow and ultimately genetic structure. 


\section{Background}

One achievement of empirical population genetic studies is the survey of the genetic diversity of thousands of plant and animal species using molecular markers, first on the basis of proteins and then of DNA. This "immense outpouring of data on genetic variation" has been considered to be both a milestone, because any type of organism could be investigated using standardised molecular methods, and a "millstone around our neck", because it resulted in the "depauperization of the diversity of empirical work in evolutionary genetics" [1]. Notwithstanding possible side-effects on the development of the field, such a large dataset of species-level microevolutionary approaches should allow addressing important issues in comparative biology. However, few studies have taken advantage of this rich but heterogeneous data for drawing inferences on patterns of genetic variation and on their relation with species attributes. Among the few attempts to relate genetic diversity statistics to species attributes, some influential studies have dealt with plants (e.g. [25]). Unfortunately, these early studies neither accounted for phylogenetic inertia in the data nor for potentially confounding covariates, making it difficult to identify causal mechanisms. We recently showed that when accounting for phylogenetic signal and covariation between traits, the only species trait that consistently predicted genetic structure was the mating system: selfing species tend to build up more genetic structure than outcrossing species [6]. Mating system was also shown to be the best predictor of plant genetic diversity [7]. However, mating system was not quantified precisely in these studies $[2-4,7]$. Furthermore, plant traits could affect genetic structure indirectly, via their effect on mating system, so predicting mating system itself on the basis of plant traits is of interest. Here we revisit the interrelations between population genetic structure, mating system and plant traits using a quantitative estimate of the mating system (i.e. outcrossing rate), while controlling phylogenetic signal and using traits as covariates.

Species genetic structure reflects the balance between divergence processes and cohesion processes among populations. In particular, gene flow limits genetic structure, whereas genetic drift increases genetic structure. Hence, traits affecting mating system and dispersal should affect genetic structure by modifying the drift/migration equilibrium. Since traits affecting genetic structure often evolve conservatively during evolution, measures of genetic structure typically present a strong phylogenetic signal (see e.g. [6]). This does not imply that $F_{\mathrm{ST}}[8]$, which measures the mean proportion of the total genetic variance contained in a population, is an intrinsically 'heritable' feature of species. In fact, it is expected to approach equilibrium on a relatively short time scale [9], compared to speciation events. Its strong phylogenetic inertia is due to the fact that related species share similar traits influencing the distribution of genetic diversity. Once phylogeny is controlled for when testing relationships between plant traits and genetic structure, $F_{\mathrm{ST}}$ (as measured at biparentally-inherited nuclear markers) has been shown to depend mostly on the inbreeding coefficient $\left(F_{\text {IS }}\right)$ and the mating system, whereas life form or perenniality appear to affect genetic structure only indirectly, through their effects on the mating system and inbreeding [6].

Mating system and inbreeding have long been known to influence species population genetic structure $[2,4,6,10,11]$. But only qualitative classifications of plant mating systems (selfed, mixed and outcrossed) have been used to study this relationship $[2,4,6]$. The classification of mating system on the basis of floral morphology can lead to false attributions and does not provide any quantitative measure of actual outcrossing rates. Direct analyses of offspring genotypic data at several gene loci allow a much more precise quantification of multilocus outcrossing rates $t_{\mathrm{m}}[12]$. Such quantitative measures of mating system should help study the association between plant traits, mating system, inbreeding and $F_{\mathrm{ST}}$.

Mating system can affect the distribution of genetic diversity in different ways, in particular by its effect on pollenmediated gene flow and by its effect on genetic drift within population. This is because selfing can (i) lower gene flow among populations by limiting pollen-mediated gene flow (as pollen used for self-pollination does not contribute to gene flow) and (ii) increase inbreeding, thereby reducing effective population size $N_{e}$ and increasing genetic drift [13]. Which of these two effects predominates in plants is typically not known. The definition of an alternative measure of $F_{\mathrm{ST}}$ not affected by the reduction of $N_{e}$ due to inbreeding would help to evaluate their respective influence.

Mating system is related with inbreeding in a complex, interdependent way: while outcrossing rate should have a strong impact on inbreeding, this factor, in turn, directly influences the evolution of the mating system. Indeed, the main factor controlling mating system evolution appears to be inbreeding depression, the detrimental effects of close inbreeding on fitness [14]. In plants, inbreeding depression affects inbred (especially selfed) progeny, particularly during the earliest stages of the plant's life cycle [15]. Hence, the inbreeding coefficient $\left(F_{\text {IS }}\right)$ of adult plants integrates information not only on selfing rate [16] but also on inbreeding depression. The selective removal of inbreds limits genetic drift and hence indirectly genetic structuring. When pollen and seed dispersal are limited, resulting in intra-population structure, $F_{\text {IS }}$ can also be affected by biparental inbreeding. Hence, comparing the expected inbreeding coefficient due to selfing, $F_{e^{\prime}}$, with the 
$F_{\text {IS }}$ observed at the adult stage allows testing the impact of both inbreeding depression and biparental inbreeding on population genetic structure.

Inbreeding depression could depend on plant traits and is typically stronger in perennials than in annuals [17-19]. Among the models proposed to explain the relationships between plant traits and inbreeding depression, the Tmodel of plant mating system evolution states that the per-generation mutation rate of a plant is a function of the number of mitoses that occur from zygote to gamete. High-T plants (typically, high-stature plants) should accumulate more mutations during their lifetime and their offspring should therefore show more inbreeding depression than low-T plants (low-stature plants) [17], thereby selecting for outcrossing. Alternatively, mating system could depend not so much on the per-generation mutation rate but on generation time per se [20]. This is expected if inbreeding depression had particularly detrimental effects in long-lived plants (for instance because it has multiplicative effects across years, [21]). Finally, generation time rather than stature could drive mating system evolution if the survival of short-lived plants but not of long-lived ones would depend on reproductive assurance conferred by selfing.

In this study, we have gathered data on the partitioning of diversity within and among populations $\left(F_{\mathrm{ST}}\right)$, on individual inbreeding $\left(F_{\mathrm{IS}}\right)$, on the mating system (based on a quantitative estimate, the outcrossing rate $t_{\mathrm{m}}$ ), and on some key plant traits (stature, growth form, perenniality, mode of pollen dispersal) for 263 plant species. A characterization of the correlation structure among these variables using phylogenetically-controlled regression methods should provide insights into the determinants of plant genetic structure. In addition, using an alternative to $F_{\mathrm{ST}}$ that controls for the impact of inbreeding on genetic differentiation, we will attempt to distinguish the effects of the mating system on gene flow and on genetic drift. Finally, we will test the occurrence of biparental inbreeding and of selection against inbreds to assess their relevance in explaining the relationships between population genetic structure, mating system and plant traits.

\section{Methods}

\section{The database}

A systematic search in the peer-reviewed literature $[17,22]$ yielded 263 plant species for which the following information were available: (i) genetic structure at nuclear markers, as measured by the $F_{\mathrm{ST}}$ index, (ii) inbreeding (or heterozygote deficit), as measured by the $F_{\text {IS }}$ index, (iii) mating system, as measured by the multilocus outcrossing rate $t_{\mathrm{m}}$ (additional file 1). Estimates of outcrossing rate that exceeded 1 (which is technically possible using unbiased estimators) were set to 1 because all reported values did not use the same method of estimation. $F_{\mathrm{ST}}$ estimates were based on allozymes for 216 species and on nuclear microsatellites for 33 species. Although the higher mutation rate at microsatellite loci might sometimes violate the assumption that mutation is negligible relative to migration [23], no difference in $F_{\mathrm{ST}}$ due to the type of marker was detected (results not shown).

\section{An alternative measure of $\mathrm{F}_{S T}$ not affected by the reduction of $\mathrm{N}_{\mathrm{e}}$ due to inbreeding}

In a neutral island model, $F_{\mathrm{ST}} /\left(1-F_{\mathrm{ST}}\right)=1 /\left(4 N_{\mathrm{e}} \cdot m\right)$ at equilibrium, where $m$ is the migration rate among populations. Therefore, selfing is expected to increase $F_{\mathrm{ST}}$ for at least two reasons: (i) selfing can reduce $m$ by limiting pollen-mediated gene flow among populations (in strictly selfing species, only seed dispersal contributes to the overall gene dispersal), and (ii) as a consequence of inbreeding, selfing should reduce $N_{e}$ by a factor of $1 /\left(1+F_{\text {IS }}\right)$ [13]. Hence, when the within-population heterozygote deficit $F_{\text {IS }}$ is positive, $N_{e}=N_{e}{ }^{\prime} /\left(1+F_{\text {IS }}\right)$, where $N_{e}{ }^{\prime}$ is the expected effective population size in the absence of inbreeding $\left(N_{e}{ }^{\prime}\right.$ is the reciprocal of the probability that two gametes contributing to random separate adults come from the same parent). To distinguish the two effects of selfing on genetic structure, we define an alternative measure, $F_{\mathrm{ST}}{ }^{\prime}=F_{\mathrm{ST}} /$ $\left[\left(1+F_{\mathrm{IS}}\right)\left(1-F_{\mathrm{ST}}\right)\right]$, closely related to the parameter $\rho[24]$. Like $\rho, F_{\mathrm{ST}}{ }^{\prime}$ is not affected by the reduction of $N_{\mathrm{e}}$ due to inbreeding because $F_{\mathrm{ST}^{\prime}} /\left(1-F_{\mathrm{ST}^{\prime}}\right)=1 /\left(4 \mathrm{~N}_{\mathrm{e}}{ }^{\prime} \cdot m\right)$ in an island model at equilibrium. Hence, under a neutral model, selfing will increase $F_{\mathrm{ST}}$ ' only if it reduces $m$ by limiting pollen-mediated gene flow.

\section{Plant traits}

For each species (additional file 1), information on the following traits was gathered (either from the original publications, by contacting directly the authors of the original articles, in floras or by searching in specialised web sites):

- Species stature, i.e. plant size, expressed in meters. We expect a positive relationship between the stature of the plant and the dispersal ability (through pollen and seeds).

- Species growth form, classified as woody or herbaceous. Succulent species like Hedysarum carnosum and Melocactus curvispinus, which are rare in our database, were grouped with woody species.

- Species perenniality, corresponding to the distinction between short-lived species (annual and biennial species) and long-lived species (perennials). Note that growth form and perenniality, although strongly correlated (all woody plants are perennials), group different species, since herbaceous plants can be either short-lived or longlived. Those species described in the literature as either 
short-lived or long-lived species (e.g. depending on the environment) were classified as long-lived species.

- Species mode of pollen dispersal, coded as biotic (insects, bats, birds) or abiotic (wind or water). Both biotic and abiotic pollen dispersal were described for Cocos nucifera and for Castanea sativa; they were grouped together with species having abiotic mode of pollination.

The analysis of the relationship between genetic structure (or mating system) and plant traits depends on the identification of the most relevant traits. In this respect, it would have been preferable to include generation time rather than some of its surrogates such as perenniality in the analyses. Similarly, the assignment of mode of pollination into discrete categories (abiotic and biotic) can be criticised as it is not always based on field observations and ignores the potential for mixed dispersal factors [25]. However, such information is generally not available in the literature.

\section{Phylogenetic tree}

A phylogenetic supertree (additional file 2) was built using as backbone (up to the family level) the updated version of the plant phylogenetic tree published by the angiosperm phylogeny group [26]. The details of the topology at lower taxonomic levels were then grafted according to phylogenetic information obtained from various sources, generally from specific phylogenetic studies at the family level or below [27-45]. Nevertheless some phylogenetic relationships were left as soft polytomies when it was not possible to resolve the topology due to lack of published information. Given the different sources of phylogenetic information it was not possible to determine branch lengths which were therefore set to 1 , an assumption that generally performs well for phylogenycontrolled comparative studies [46].

\section{Statistical analyses}

Transformation of the variables

Qualitative variables were coded as dummy: for growth form, herbaceous $=0$ and woody $=1$; for perenniality, short-lived $=0$ and long-lived $=1$; for mode of pollen dispersal, abiotic $=0$ and biotic $=1$. To improve normality of the continuous variables $\left(F_{\mathrm{ST}}, F_{\mathrm{ST}^{\prime}}, F_{\mathrm{IS}}, t_{\mathrm{m}}\right.$ and stature $)$ we used the option "Box-Cox-Bartlett transformations" included in the $\mathrm{R}$ Package for Multivariate and Spatial Analysis Version 4.0 [47].

\section{Transformation of the data into phylogenetically-independent contrasts}

To control for the phylogenetic relationships among species, data were transformed into phylogenetically independent contrasts (PICs, [48]) using the PDAP module [49] included in Mesquite software [50]. Phylogeny con- trolled methods are statistically conservative and tend to perform better in cross-species comparisons than nonphylogenetically controlled methods, even when their assumptions are violated (like the non-Brownian mode of evolution of the characters or inconsistencies of the chosen phylogenetic hypothesis) [51].

\section{Regression analyses}

Regression analyses were conducted under the following assumptions, based on population genetics theory. (i) The outcrossing rate $\left(t_{\mathrm{m}}\right)$ can be influenced by plant traits. (ii) Individual inbreeding within population $\left(F_{\mathrm{IS}}\right)$ can be influenced by plant traits and by $t_{\mathrm{m}}$. (iii) Genetic differentiation $\left(F_{\mathrm{ST}}\right.$ and $\left.F_{\mathrm{ST}}{ }^{\prime}\right)$ can be influenced by plant traits, $t_{\mathrm{m}^{\prime}}$ and $F_{I S}$. Regressions analyses were performed on the raw data (TIPs analyses: comparison of the values taken at the tips of the tree) and on the independent contrasts using SYSTAT, version 10.2.05 [52]. For PICs analyses, regressions were forced through the origin [48]. Multiple regression analyses were performed with the forward stepwise regression option to integrate in the model the independent variables as a function of their importance (i.e. their degree of relatedness with the dependent variable).

Species were considered mixed mating species when 0.1 $<t_{\mathrm{m}}<0.9$ (number of species $N=129$ ) or outcrossed species when $t_{\mathrm{m}}>0.9(N=129)$. Only five selfed species $\left(t_{\mathrm{m}}\right.$ $<0.1$ ) were present in the database, so no selfed category was used.

Assessing biparental inbreeding and inbreeding depression For the subset of non-outcrossed species for which both $t_{\mathrm{m}}$ and $t_{\mathrm{s}}\left(t_{\mathrm{s}}\right.$ is the mean of single locus outcrossing rate) were available (80 species), we apply a sign test on the difference $t_{\mathrm{m}}-t_{\mathrm{s}}$ to check for the presence of biparental inbreeding. A positive difference $\left(t_{\mathrm{m}}>t_{\mathrm{s}}\right)$ will demonstrate the presence of biparental inbreeding as $t_{\mathrm{s}}$ should be more affected by biparental inbreeding than the multi-locus estimator $t_{\mathrm{m}}$ (due to an over-estimation of the selfing rate when polymorphism is low, [12]).

The expected inbreeding $F_{e}$ would correspond to the fixation index $\left(F_{\text {IS }}\right)$ if selfing were the sole factor causing deviation from Hardy-Weinberg equilibrium. For a mixed mating model in the absence of inbreeding depression, $F_{\mathrm{e}}$ is estimated as: $F_{e}=\left(1-t_{\mathrm{m}}\right) /\left(1+t_{\mathrm{m}}\right)$ [16]. Differences in the levels of inbreeding coefficient between seed and adult cohorts would suggest that other factors than selfing influence genotypic frequencies [53]. High $F_{\mathrm{IS}}$ estimates relative to the expectation could be caused by biparental inbreeding, whereas low estimates could reflect the impact of inbreeding depression. To test for statistical trends in the distribution of $F_{e}-F_{I S}$ for all species and then separately for each growth form by perenniality category (short-lived herbaceous, long-lived herbaceous and 
woody species), we applied a sign test over all species except outcrossed ones. Predominantly outcrossed species were excluded from these analyses because the seeds produced are not inbred, so that inbreeding depression, even if it exists, cannot manifest itself.

Under inbreeding depression $\left(\delta \equiv 1-\mathrm{w}_{\mathrm{i}} / \mathrm{w}_{\mathrm{o}}\right.$ where $\mathrm{w}_{\mathrm{i}}$ and $\mathrm{w}_{\mathrm{o}}$ are the fitness of inbred and outbred individuals, respectively), the expected inbreeding is [53]:

$$
F_{\mathrm{IS}}(\delta, t)=\frac{(1-\delta)(1-t)}{1-\delta+t+t \delta}
$$

For each growth form by perenniality category, an average value of $\delta$ was estimated by least square fitting of this equation on the observed $F_{\mathrm{IS}}$ and $t_{\mathrm{m}}$ values. This approach neglects inter-species variation but captures general trends of the intensity of inbreeding depression according to growth form and perenniality.

\section{Results}

\section{Taxonomic coverage}

The 263 species are distributed into 155 genera and 73 families; there are 63 gymnosperms genera (all conifers) and 92 angiosperms genera (seven magnoliids, 22 monocots, 63 eudicots). Four botanical families are particularly represented (families that contain more than 5\% of the species included in the database): Asteraceae, Fabaceae, Myrtaceae (mainly the genus Eucalyptus) and Pinaceae; together they include $47 \%$ of the species of the data set.

\section{General patterns}

The mean values of $t_{\mathrm{m}^{\prime}} F_{\mathrm{IS}}$ and $F_{\mathrm{ST}}$ as a function of growth form, perenniality, a combination of perenniality/growth form and pollination mode are provided in Figure 1 and 2 (and see additional file 3 ). The distribution of $t_{\mathrm{m}^{\prime}}, F_{\mathrm{IS}}$ and $F_{\mathrm{ST}}$ clearly depends on plant traits. This is particularly remarkable for $t_{\mathrm{m}}$ : long-lived woody species are generally outcrossed, in contrast to short-lived herbaceous species, for which the mating system ranges from fully selfing to fully outcrossing. Values of $F_{\mathrm{ST}}, F_{\mathrm{IS}}$ and $t_{\mathrm{m}}$ covary: when $F_{\mathrm{ST}}$ decreases (for example $F_{\mathrm{ST}}$ is lower for woody species than for herbaceous species), then $F_{\text {IS }}$ also decreases (woody species present a lower inbreeding coefficient than herbaceous species) while $t_{\mathrm{m}}$ increases (woody species are more outcrossed than herbaceous species). Nevertheless most of the statistically significant differences among categories in TIPs analyses disappear when the phylogenetic signal is controlled for (PICs analyses). The only relationships that remain significant are those between growth form and $F_{\mathrm{ST}}$, between perenniality and $F_{\mathrm{IS}}$, and between growth form/ perenniality and $t_{\mathrm{m}}$.

\section{Relationships among traits}

Stature, growth form and perenniality were found to be positively associated using both TIPs and PICs analyses (Figure 3). In contrast, TIPs but not PICs analyses identify significant relationships between pollination mode and the other traits, which are thus likely due to the phylogenetic conservatism of the studied traits.

\section{Relationships between traits and $F_{S T}$ (figure $I$, table $I$ and additional file 4)}

All four traits studied are strongly related with $\mathrm{F}_{\mathrm{ST}}$ in TIPs analyses (regression coefficient of $\mathrm{F}_{\mathrm{ST}}$ as a function of stature is $-0.45, \mathrm{P}<0.001)$. Herbaceous, short-lived, low-stature, biotically-pollinated, mixed-mating species present higher levels of genetic structure than woody, long-lived, high-stature, abiotically-pollinated, allogamous species. The decomposition of herbaceous species into short-lived and long-lived species demonstrates the impact of the perenniality within herbaceous species, as short-lived herbaceous species present higher $F_{S T}$ than long-lived herbaceous species (figure 1). When the phylogenetic signal is controlled for, $\mathrm{F}_{\mathrm{ST}}$ depends on $\mathrm{F}_{\mathrm{IS}}, \mathrm{t}_{\mathrm{m}^{\prime}}$ growth form and species stature (table 1 ). $\mathrm{F}_{\mathrm{ST}}$ increases when $\mathrm{F}_{\mathrm{IS}}$ increases and decreases when $\mathrm{t}_{\mathrm{m}}$ increases. $\mathrm{F}_{\mathrm{ST}}$ is negatively related to plant stature, and herbaceous species have lower $\mathrm{F}_{\mathrm{ST}}$ than woody species. The pollination mode has no influence on $\mathrm{F}_{\mathrm{ST}}$ (table 1). In long-lived species, $\mathrm{F}_{\mathrm{ST}}$ is also negatively associated with $\mathrm{t}_{\mathrm{m}}$ and positively with $\mathrm{F}_{\mathrm{IS}}$ and with species stature, whereas long-lived woody species have lower $\mathrm{F}_{\mathrm{ST}}$ than long-lived herbaceous species (additional file 4). In a multiple regression framework (PICs, table 1), variation in $\mathrm{t}_{\mathrm{m}}$ and $\mathrm{F}_{\mathrm{IS}}$ accounts for variation in $\mathrm{F}_{\mathrm{ST}}$ but the growth form and the stature do not enter into the model once $t_{m}$ and $F_{I S}$ are included. Additional file 4 indicates that for herbaceous and woody species the main influencing factor is $\mathrm{F}_{\mathrm{IS}}$ (the effect of $\mathrm{t}_{\mathrm{m}}$ disappears in the multiple regression).

\section{Relationships between traits and $F_{S T}$ (table $I$ and additional file 4)}

As for $F_{\mathrm{ST}}, F_{\mathrm{ST}}$ ' depends on $F_{\mathrm{IS}}, t_{\mathrm{m}^{\prime}}$ stature and growth form (table 1). The strength of the relationship between $F_{\mathrm{ST}}{ }^{\prime}$ and $t_{\mathrm{m}}$ and between $F_{\mathrm{ST}}$ and $F_{\mathrm{IS}}$ is lower than the respective relationships with $F_{\mathrm{ST}}$. Contrarily to $F_{\mathrm{ST}}$, in a multiple regression with stepwise selection, $t_{\mathrm{m}}$ is the main explanatory variable of $F_{\mathrm{ST}}$ ' and $F_{\mathrm{IS}}$ does not enter the model once $t_{\mathrm{m}}$ is accounted for. The comparison between $F_{\mathrm{ST}}$ and $F_{\mathrm{ST}}{ }^{\prime}$ is particularly interesting when focusing on species from different categories (long-lived, herbaceous, woody, additional file 4). In long-lived species, $F_{\mathrm{ST}}$ ' is no longer associated with $F_{\mathrm{IS}}$. By contrast $F_{\mathrm{ST}}$ ' is still related with $F_{\mathrm{IS}}$ in herbaceous species, although $t_{\mathrm{m}}$ remains the main explanatory variable. 

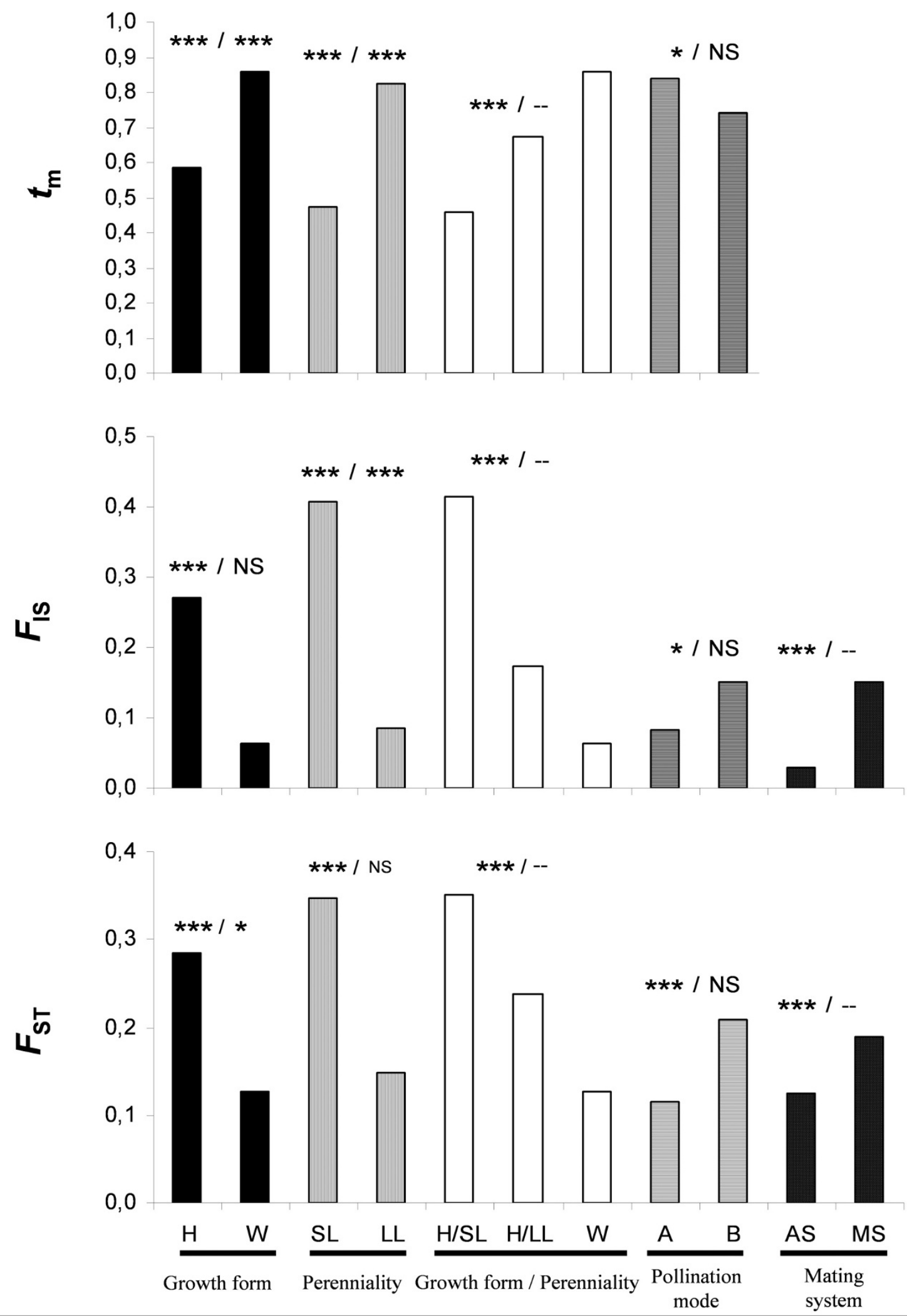

Figure I (see legend on next page) 
Figure I (see previous page)

Mean values of $t_{m}, F_{I S}$ and $F_{S T}$ as a function of growth form (H: herbaceous, W: woody), perenniality (SL: shortlived, LL: long-lived), the combination of growth form and perenniality (H/SL: herbaceous short-lived, H/LL: herbaceous long-lived, W/LL: woody long-lived), the mode of pollen dispersal (A: abiotic, B: biotic) and outcrossing rate (MS: mixed mating species, AS: allogamous species). For each category the $P$-value associated with the statistical test is indicated by $* * * P<0.001$, ** $0.00 \mathrm{I}<P<0.0 \mathrm{I}, * 0.0 \mathrm{I}<P<0.05$ and NS for $P>0.05$. At the left part of the slash the $P$-value corresponds to the TIPs test and at the right to the PICs test. "--" indicates an absence of statistical test. Standard error values for each category is available in the additional file 3.
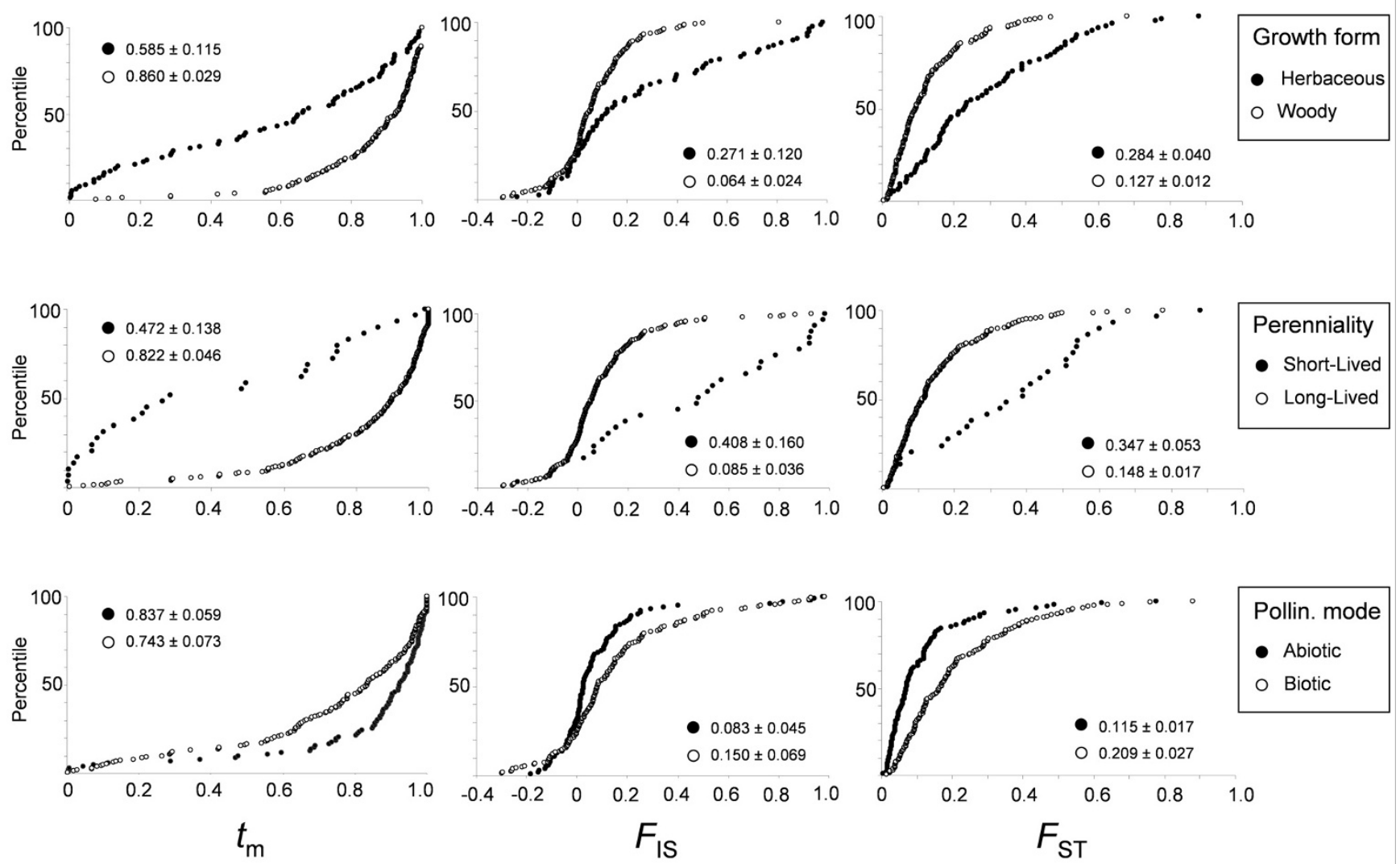

Pollin. mode

- Abiotic

- Biotic

\section{Figure 2}

Distribution of $t_{\mathrm{m}}, F_{\mathrm{IS}}$ and $F_{\mathrm{ST}}$ according to growth form, perenniality and pollination mode categories (percentile versus ranked $t_{\mathrm{m}}$-estimate, $F_{\mathrm{IS}}$-estimate and $F_{\mathrm{ST}}$-estimate data). 


\section{TIPs}

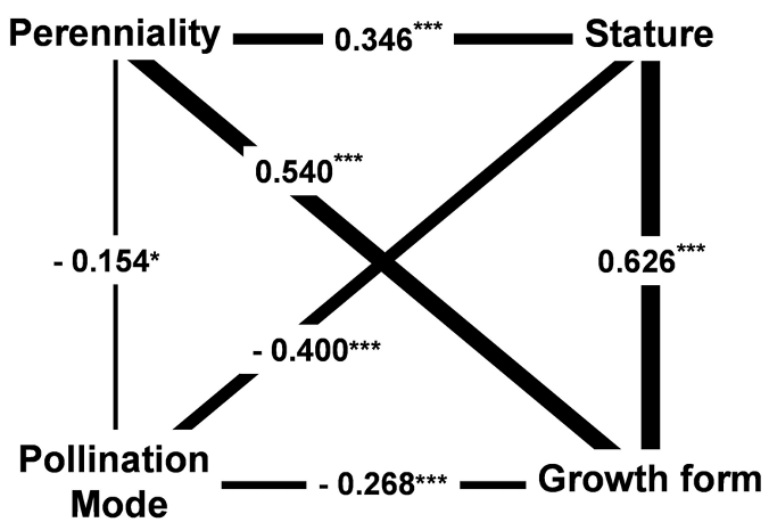

PICs

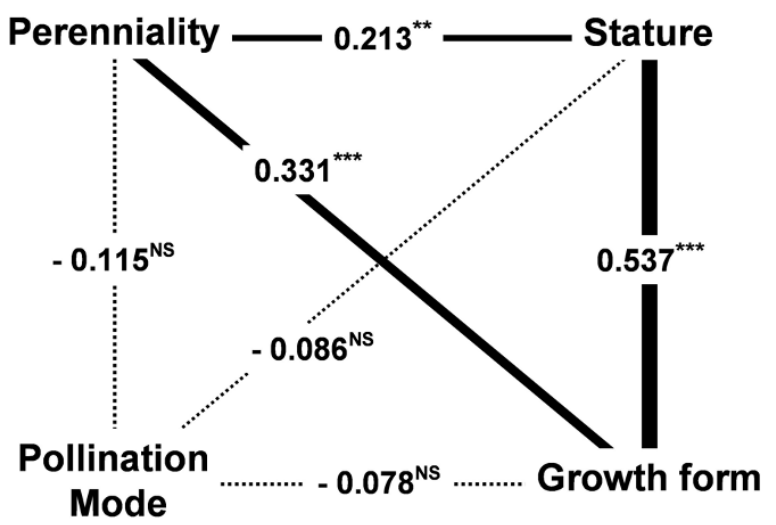

Figure 3

Conventional regressions analyses (TIPs) on the left and phylogenetically-controlled regression analyses (PICs) on the right, among plant traits: growth form, perenniality, pollination mode and stature. $* * * P<0.00 \mathrm{I}$, $* * 0.001<P<0.01$, * $0.01<P<0.05$ and NS for $P>0.05$.

\section{Relationships between traits and FIS (figure I, tables I and 2)}

All traits are correlated with the inbreeding coefficient $F_{\text {IS }}$ in TIPs analyses (figure 1 ; regression coefficient $F_{\text {IS }}$ as a function of stature is $-0.27, P<0.001)$. Herbaceous, shortlived, low-stature, biotically-pollinated, mixed-mating species present higher inbreeding coefficient than, respectively, woody, long-lived, high-stature, abiotically-pollinated, allogamous species. Moreover, short-lived herbaceous species present higher $F_{\text {IS }}$ than long-lived herbaceous species (figure 1). Based on PICs analyses, the inbreeding coefficient depends mainly on the outcrossing rate, with outcrossed species displaying lower inbreeding (table 1). But perenniality also remains a statistically significant predictive factor of the level of $F_{\text {IS }}$, with perennial species characterised by lower inbreeding. By contrast, there is no residual relationship between the size of the plants and $F_{\text {IS. }}$. The outcrossing rate $t_{\mathrm{m}}$ is negatively associated with $F_{\text {IS }}$ for all categories of plants (long-lived, herbaceous and woody species, table 2). In addition, for herbaceous species, there is an effect of perenniality, but it does not persist when $t_{\mathrm{m}}$ is accounted for (table 2).

Table I: Phylogenetically-controlled regression analyses between $t_{\mathrm{m}}, F_{\mathrm{IS}}, F_{\mathrm{ST}}, F_{\mathrm{ST}}{ }^{\prime}$ and other variables

\begin{tabular}{|c|c|c|c|c|c|c|c|c|}
\hline & \multicolumn{2}{|l|}{$\boldsymbol{t}_{\mathrm{m}}$} & \multicolumn{2}{|l|}{$\boldsymbol{F}_{\mathrm{IS}}$} & \multicolumn{2}{|l|}{$\boldsymbol{F}_{\mathrm{ST}}$} & \multicolumn{2}{|l|}{$\boldsymbol{F}_{\mathrm{ST}}^{\prime}$} \\
\hline & $\mathrm{R} \ddagger$ & $\Delta \mathrm{R}^{2 \dagger}$ & $\mathrm{R} \neq$ & $\Delta R^{2 \dagger}$ & $\mathrm{R} \ddagger$ & $\Delta \mathrm{R}^{2 \dagger}$ & $\mathrm{R} \neq$ & $\Delta \mathrm{R}^{2 \dagger}$ \\
\hline$t_{\mathrm{m}}$ & NC & & $-0.51 \mid * * *$ & 0.261 & $-0.343^{* * *}$ & 0.034 & $-0.272 * * *$ & 0.073 \\
\hline$F_{I S}$ & NC & & NC & & $0.36 I^{* * *}$ & 0.130 & $0.213^{* * * *}$ & -- \\
\hline Stature & $0.203 * * *$ & -- & $-0.059 \mathrm{NS}$ & & $-0.135^{*}$ & -- & $-0.134^{*}$ & -- \\
\hline Growth form ${ }^{a}$ & $0.339 * * *$ & 0.054 & $-0.115^{N S}$ & & $-0.146 *$ & -- & $-0.138^{*}$ & -- \\
\hline Perenniality ${ }^{b}$ & $0.362^{* * *}$ & 0.131 & $-0.293^{* * * *}$ & 0.013 & $-0.115 \mathrm{NS}$ & & $-\left.0.08\right|^{N S}$ & \\
\hline Pollination mode ${ }^{c}$ & $0.019^{N S}$ & & $-0.004^{N S}$ & & $0.04 \mid \mathrm{NS}$ & & $0.042^{\mathrm{NS}}$ & \\
\hline
\end{tabular}

$* * * P<0.001, * * 0.001<P<0.01, * 0.01<P<0.05$ and NS for $P>0.05$. NC indicates variables not considered as explanatory variable. a Herbaceous species were coded 0 and woody species I; b Short-lived species (annuals and biannuals) were coded 0 , and long-lived species (perennial species) were coded I; c The mode of pollination was coded 0 for abiotic (wind- or water-dispersed) and I for biotic (animal-dispersed) $\ddagger$ correlation coefficient of simple regression analyses

t multiple regression analyses (stepwise option using all significant variables from the simple regression analyses): $\Delta \mathrm{R}^{2}$ represents the gain of $\mathrm{R}^{2}$ (proportion of variation explained by the variables) when the variable is incorporated into the model, "--" indicates that the variable does not enter in the model, after the integration of the most explicative variables. 
Table 2: Phylogenetically-controlled regression analyses between $F_{\text {IS }}$ and other variables

\begin{tabular}{|c|c|c|c|c|c|c|}
\hline \multirow[b]{2}{*}{ Variable } & \multicolumn{2}{|c|}{ Long lived species } & \multicolumn{2}{|c|}{ Herbaceous } & \multicolumn{2}{|l|}{ Woody } \\
\hline & $R \ddagger$ & $\Delta R^{2 \dagger}$ & $\mathrm{R}$ & $\Delta R^{2 \dagger}$ & $\mathrm{R}$ & $\Delta R^{2 \dagger}$ \\
\hline$t_{\mathrm{m}}$ & $-0.354 * * * *$ & & $-0.780 * * *$ & 0.608 & $-0.276 * * *$ & \\
\hline Stature & $0.004 \mathrm{NS}$ & & $-0.192^{\mathrm{NS}}$ & & $0.022^{\mathrm{NS}}$ & \\
\hline Growth form d & $-0.028 \mathrm{NS}$ & & NC & & NC & \\
\hline Perenniality e & NC & & $-0.410 * * *$ & -- & NC & \\
\hline Pollination mode $f$ & $-0.058 \mathrm{NS}$ & & $0.094 \mathrm{NS}$ & & $-0.045 \mathrm{NS}$ & \\
\hline
\end{tabular}

Same legend as table I.

\section{Relationships between traits and outcrossing rate tm (figure I, table I and 3 and additional file 5)}

The outcrossing rate is positively associated with all four traits studied, although less strongly with pollination mode (figure 1 ; regression coefficient of $t_{\mathrm{m}}$ as a function of stature is $0.44, P<0.001$, in TIPs analyses). Woody, longlived, high-stature, abiotically-pollinated species have higher outcrossing rates than herbaceous, short-lived, low-stature, biotically-pollinated species. The associations of $t_{\mathrm{m}}$ with growth form and perenniality persist in PICs analyses, but not that with pollination mode, indicating that previously identified relationships between mating system and pollination mode might be due to pseudoreplication [22] (table 3). Additionally, taller species have higher outcrossing rates (table 1 ), but not if we restrict the analyses to woody plants (table 3 ). Based on multiple regression analyses, the strongest relationship was found between mating system and perenniality: annual or biannual species present lower outcrossing rates than perennial species (table 1). Once this variable is taken into account, growth form is still an explanatory variable of $t_{\mathrm{m}}$ despite the fact that most herbaceous species are shortlived species and that all woody species are long-lived species. The additional information stems probably from the difference between herbaceous and woody perennials. To summarize, as already mentioned by [20], average $t_{\mathrm{m}}$ increases in the following sequence: short-lived herbaceous species, long-lived herbaceous species, woody species (figure 1).

\section{Presence of biparental inbreeding}

A positive signal of biparental inbreeding over all species is revealed by the sign test applied on the difference $t_{\mathrm{m}}-t_{\mathrm{s}}$ (124 cases with $t_{\mathrm{m}}>t_{\mathrm{s}^{\prime}}$ versus only 33 with $t_{\mathrm{m}}<t_{\mathrm{s}^{\prime}} P<$ $0.001)$. Few informative data are available for short-lived herbaceous species, making it difficult to test for a trend (only five cases, all with $t_{\mathrm{m}}>t_{\mathrm{s}^{\prime}} P=0.063$ ). For perennial species the trend is significant (for herbaceous species: 16 cases versus two with $t_{\mathrm{m}}>t_{\mathrm{s}^{\prime}} P=0.001$ and for woody species: 45 versus 10 with $\left.t_{\mathrm{m}}>t_{\mathrm{s}^{\prime}} P<0.001\right)$. Differences in levels of biparental inbreeding among categories are not significant (data not shown).

\section{Difference between observed and predicted inbreeding coefficient}

Figure 4 illustrates the observed inbreeding compared to that expected at equilibrium if selfing was the sole cause of inbreeding $\left(F_{\mathrm{e}}=\left[1-t_{\mathrm{m}}\right] /\left[1+t_{\mathrm{m}}\right]\right)$. There is a global trend towards $F_{\mathrm{IS}}<F_{\mathrm{e}}$ over all species, which indicates a selection against inbred individuals (94 cases, compared to 48 with

Table 3: Phylogenetically-controlled regression analyses between $t_{m}$ and other variables

\begin{tabular}{|c|c|c|c|c|c|c|}
\hline \multirow[b]{2}{*}{ Variable } & \multicolumn{2}{|c|}{ Long lived species ${ }^{\mathrm{a}}$} & \multicolumn{2}{|c|}{ Herbaceous $^{b}$} & \multicolumn{2}{|l|}{ Woodyc } \\
\hline & $R \neq$ & $\Delta R^{2} \dagger$ & $\mathrm{R}$ & $\Delta R^{2} \dagger$ & $\mathrm{R}$ & $\Delta R^{2 \dagger}$ \\
\hline Stature & $0.162 *$ & -- & $0.152^{\mathrm{NS}}$ & & $0.029 \mathrm{NS}$ & \\
\hline Growth form d & $0.239 * * *$ & 0.057 & NC & & NC & \\
\hline Perenniality e & NC & & $0.423^{* * * *}$ & & NC & \\
\hline Pollination mode $f$ & $0.082^{\mathrm{NS}}$ & & $0.027 \mathrm{NS}$ & & $0.020 \mathrm{NS}$ & \\
\hline
\end{tabular}

a $\mathrm{N}=230 \mathrm{~b} \mathrm{~N}=76 \mathrm{cN}=185$

$0.0 \mathrm{I}<P<0.05$ and $\mathrm{NS}$ for $P>0.05$.

d Herbaceous species were coded 0 and woody species I; e Short-lived species (annuals and biannuals) were coded 0 , and long-lived species (perennials species) were coded I; ${ }^{\mathrm{T}}$ The mode of pollination was coded 0 for abiotic (wind- or water-dispersed) and I for biotic (animal-dispersed) $\ddagger$ correlation coefficient of simple regression analyses

t multiple regression analyses (stepwise option using all significant variables from the simple regression analyses): $\Delta R^{2}$ represents the gain of $R^{2}$ (proportion of variation explained by the variables) when the variable is incorporated into the model, "--" indicates that the variable does not enter in the model, after the integration of the most explicative variables. 


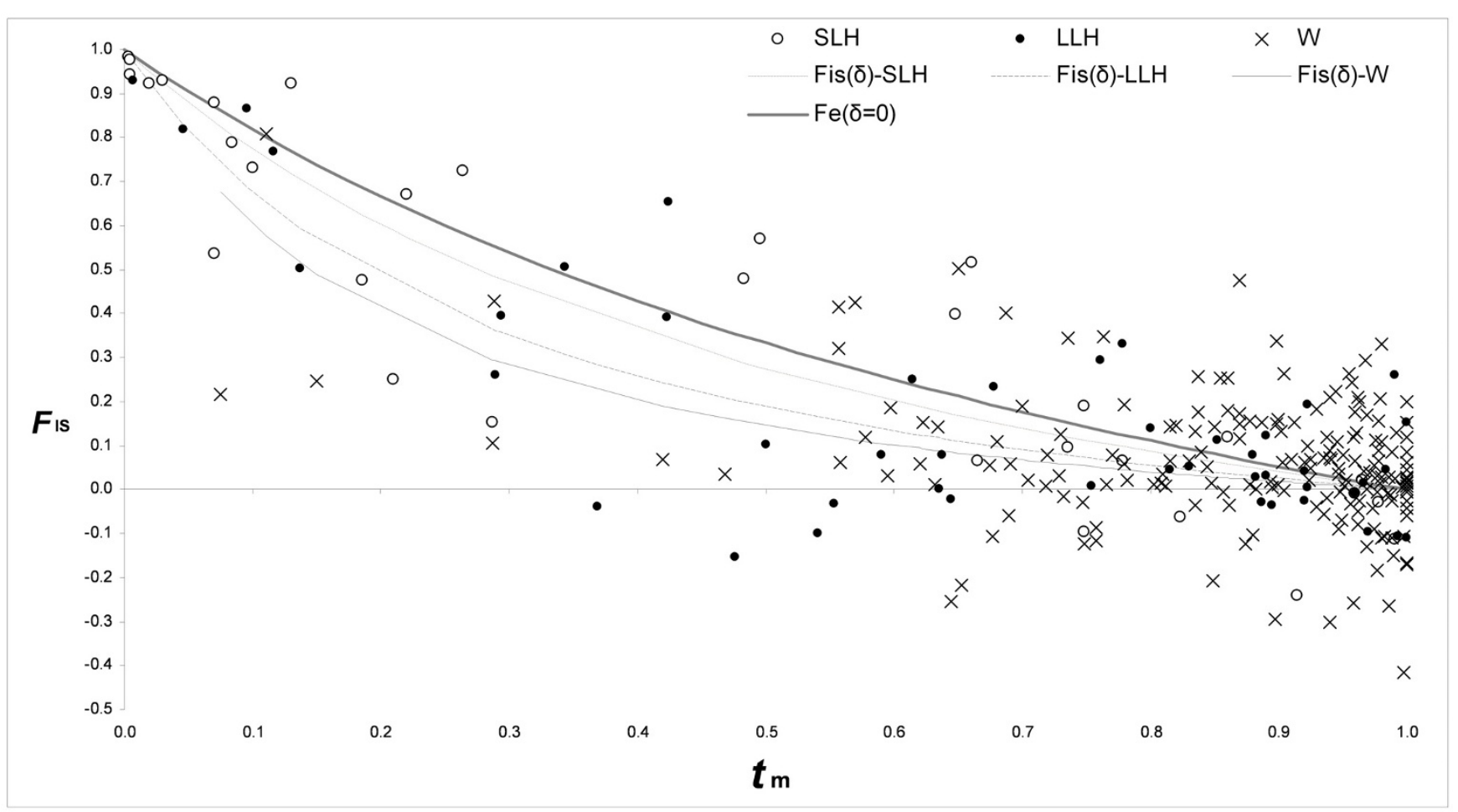

Figure 4

Distribution of $\boldsymbol{F}_{\mathrm{IS}}$ according to $\boldsymbol{t}_{\mathrm{m}}$. The open circles correspond to short-lived herbaceous species, the closed circles to long-lived herbaceous species and the crosses to woody species. The thick continuous line represents $F_{\mathrm{e}}$, which is the expected $F_{1 S}$ based on the observed $t_{m}$, assuming a mixed-mating system at equilibrium without inbreeding depression. The other lines correspond to the best-fitting curves according to equation I after adjusting the level of inbreeding depression, $\delta$, for shortlived herbaceous species (short-hatched line), perennial herbaceous species (long-hatched line) and woody species (continuous line).

$\left.F_{\mathrm{IS}}>F_{e^{\prime}} P<0.001\right)$. In short-lived herbaceous species, $F_{\mathrm{IS}}$ is very close to $F_{\mathrm{e}^{\prime}}$ whereas for perennial species a majority of species have $F_{\mathrm{IS}}<F_{\mathrm{e}^{\prime}}$ especially when $0.1<t_{\mathrm{m}}<0.9$ (i.e. in mixed-mating species). There was no significant difference between $F_{\mathrm{IS}}$ and $F_{\mathrm{e}}$ in short-lived species (16 cases with $F_{\mathrm{IS}}<F_{e^{\prime}}$ compared to 10 with $F_{\mathrm{IS}}>F_{\mathrm{e}^{\prime}} P=0.33$ ), in contrast to herbaceous perennial species that present a marginally significant trend (23 cases with $F_{\mathrm{IS}}<F_{\mathrm{e}^{\prime}}$ compared to 11 with $\left.F_{\mathrm{IS}}>F_{\mathrm{e}^{\prime}} P=0.057\right)$ and woody species that present a significant trend ( 55 cases with $F_{\mathrm{IS}}<F_{\mathrm{e}^{\prime}} \mathrm{com}$ pared to 27 with $\left.F_{\mathrm{IS}}>F_{\mathrm{e}^{\prime}} P=0.003\right)$. However, the mean of $F_{\mathrm{IS}}-F_{\mathrm{e}}$ does not differ significantly between short-lived $(M=-0.04, N=26)$ and long-lived species $(M=-0.08, N$ $=116)(P=0.30)$.

\section{Estimation of inbreeding depression}

The measures of inbreeding depression $\delta$ obtained by least square fitting of the data using the equation $F_{\mathrm{IS}}(\delta, t)=\frac{(1-\delta)(1-t)}{1-\delta+t+t \delta}[53]$ are 0.24 for short-lived herbaceous, 0.53 for long-lived herbaceous and 0.66 for woody species. These values are probably somewhat underesti- mated, given that biparental inbreeding exists in all plant categories; its effect should be to inflate $F_{\text {IS }}$ compared to the equilibrium expectation $\left(F_{e}\right)$ based on selfing rate.

\section{Discussion}

Using for the first time quantitative estimates of outcrossing rate $\left(t_{\mathrm{m}}\right)$, we confirm previous studies showing that mating system largely controls plant population genetic structure $[2,4,6,54]$. Our results, which rely on the use of independent contrasts, also show that once mating system and inbreeding are accounted for, plant traits are no longer associated with $F_{\mathrm{ST}}[6]$. We further show that mating system affects $F_{\mathrm{ST}}$ via its effect on pollen-mediated gene flow and on effective population size (i.e. drift). These two mechanisms have long been known to affect $F_{\text {ST }}[55]$ but it has generally not been possible to tell them apart. We were able to partially disentangle their effects by comparing traditional $F_{\mathrm{ST}}$ with an alternative parameter $\left(F_{\mathrm{ST}}{ }^{\prime}\right)$ that controls for the influence of inbreeding on effective population size but is not affected by the impact of the mating system on inbreeding. Under a neutral model, the negative correlation of $F_{\mathrm{ST}}$ ' with $t_{\mathrm{m}}$ indicates 
that selfing reduces pollen-mediated gene flow among populations. Hence, selfing results not only in increased genetic drift due to inbreeding but also in decreased pollen-mediated gene flow, as discussed by Ingvarsson [56]. However, $F_{\mathrm{ST}}$ ' is not significantly correlated with $t_{\mathrm{m}}$ when the analysis is restricted to long-lived species or to woody species, probably because most species are then predominantly outcrossed and a reduction of pollen flow due to selfing becomes hardly perceptible.

Selfing can also reduce $N_{e}$ by other processes than inbreeding, for instance through selective sweeps and hitchhiking, as a consequence of background selection, or because it magnifies the consequences of extinction and recolonisation $[56,57]$. This could explain the remaining association between $F_{\mathrm{ST}}$ and $F_{\mathrm{IS}}$. Indeed, controlling for the inbreeding effect of selfing did not fully account for the actual reduction of $N_{e}$ caused by selfing. Munoz et al. (Munoz F, Violle C, Cheptou P-O: Plant mating system is related to CSR strategy: from selfing ruderals to outcrossing competitors. Unpublished) demonstrated that selfing species are mainly early-successional species, suggesting that metapopulation dynamics could differ depending on the mating system.

Despite the strong impact of the mating system on $F_{\mathrm{ST}}, F_{\mathrm{IS}}$ rather than $t_{\mathrm{m}}$ is the main explanatory variable of $F_{\mathrm{ST}}$, as already apparent in our previous study [6]. However, this difference is not significant, since identical results were obtained in partial regression analyses regardless of which factor, $t_{\mathrm{m}}$ or $F_{\mathrm{IS}}$, is first included in the model (data not shown). The important point here is that both $t_{\mathrm{m}}$ and $F_{\mathrm{IS}}$ explain the $F_{\mathrm{ST}}$, showing that they contain complementary information. The outcrossing rate $t_{\mathrm{m}}$ is expected to be an accurate predictor of species inbreeding history only if outcrossing rate is stable over time, which is generally not the case. By contrast $F_{\text {IS }}$ reflects inbreeding not only in the current generation but also in previous generations [58]. Furthermore, $F_{\mathrm{IS}}$ integrates other sources of inbreeding besides that caused by selfing, such as intra-population genetic structuring (Wahlund effect, [59]) resulting in biparental inbreeding and/or selection against inbreds (inbreeding depression).

Although plant traits are not directly associated with $F_{\mathrm{ST}}$, they could still control it indirectly, via their effect on mating system and on inbreeding. This had not been tested in previous studies because accurate quantifications of mating system were missing. Here we show that there is a strong association between mating system and perenniality: in contrast to short-lived plants, most long-lived plants are outcrossed. Growth form also appears to play a role on mating system, because woody plants (which are all long-lived) are more outcrossed than perennial herbaceous plants. Interestingly, plant stature does not influ- ence outcrossing rate once perenniality and growth form are controlled for. Finally, we did not find any association between mating system and mode of pollination, in contrast to previous studies that did not use phylogenetic corrections $[20,22,60]$. Overall, the main predictor of outcrossing rate is perenniality, suggesting that there is a repeated pattern in unrelated lineages of evolutionary change towards selfing driven by short life cycles (or reciprocally an evolutionary transition towards outcrossing driven by longer life cycles). This result points to selective forces driving the evolution of plant mating systems [61].

Perenniality is related not only with mating system but also with inbreeding. Long-lived species, which are more outcrossed than short-lived species, have lower inbreeding coefficients. Interestingly, perenniality still influences the level of inbreeding $F_{\text {IS }}$ once mating system has been controlled for (i.e. a perennial species having the same outcrossing rate than an annual species tends to have less inbreeding). This might be explained by a difference between short-lived and long-lived species in their level of biparental inbreeding and/or of inbreeding depression. The first possibility implies that short-lived species are more subject to biparental inbreeding than long-lived ones, for instance due to reduced gene flow. Our data do not provide support for this hypothesis, as biparental inbreeding appears to be a general phenomenon in plant species. The second possibility implies that selection against inbreds is stronger in perennials than in non-perennials [17-19]. Our data confirm the trend of increased inbreeding depression from short-lived herbaceous to long-lived herbaceous and to woody species. Hence, $F_{I S}$ integrates information not only on selfing but also on selection against inbreds, which is associated with perenniality. This could explain why perenniality remains a significant explanatory variable of $F_{\mathrm{IS}}$ once the outcrossing rate is accounted for (table 1). Similarly, inbreeding depression might explain why $F_{I S}$ remains a significant explanatory variable of $F_{\mathrm{ST}}$ once the outcrossing rate is accounted for (table 1).

Two opposite scenarios can be proposed to explain the negative relationship between inbreeding depression and $F_{\mathrm{ST}}$. Selection against inbreds could lower $F_{\mathrm{ST}}$ by reducing the effective selfing rate and hence intra-population drift. Alternatively, genetic structure could affect inbreeding depression. A plant in a given population will receive pollen either (i) from a pollen donor from another population (external-outbred pollen, $\mathrm{P}_{\mathrm{eo}}$ ), (ii) from a pollen donor from the same population (local-outbred pollen, $\mathrm{P}_{\mathrm{io}}$ ), or (iii) from its own pollen (self-pollen, $\mathrm{P}_{\mathrm{s}}$ ). Assuming that there is no outbreeding depression, the offspring fitness should vary according to the pollen source, as follows: $\mathrm{W}_{\mathrm{eo}}>\mathrm{W}_{\mathrm{io}}>\mathrm{W}_{\mathrm{s}}$. When $F_{\mathrm{ST}}$ is low, one can expect $\mathrm{W}_{\mathrm{i} o}$ to be close to $\mathrm{W}_{\mathrm{eo}}$ because external and local pollen will be 
genetically similar. When $F_{\mathrm{ST}}$ is large, one can expect $\mathrm{W}_{\text {io }}$ to be close to $\mathrm{W}_{\mathrm{s}}$ because individuals are strongly related and the population will have already been purged from partially recessive deleterious alleles. This would result in lower inbreeding depression $\delta$ in short-lived, high- $F_{\mathrm{ST}}$ species.

The high outcrossing rate found in woody perennial is likely a strategy to avoid the deleterious effects of inbreeding. The reason why woody perennials are particularly sensitive to inbreeding remains elusive. There are two main hypotheses, one stating that deleterious effects become magnified through time, due to their multiplicative effects on fitness [18], and the other that deleterious effects depend on the number of cell divisions per cycle [17]. As cell divisions accumulate through time, the two hypotheses are difficult to distinguish. Moreover, stature is certainly a poor surrogate for the number of cell divisions [17], whereas perenniality is a poor surrogate for generation time. Nevertheless, our results do suggest that the association between stature and mating system could be a by-product of the correlation of stature with perenniality and growth form. This is illustrated by the absence of association between stature and $t_{\mathrm{m}}$ among herbaceous species and among woody species.

\section{Conclusion}

Despite imprecision associated with the measures of $F_{\mathrm{ST}}$, $F_{\mathrm{IS}}$ and $t_{\mathrm{m}}$, our study has revealed general macroevolutionary patterns emerging from the phylogenetically-controlled correlation structure of these measures with species traits. We confirm that mating system is the main determinant of $F_{\mathrm{ST}}$, whereas its impact on $F_{\mathrm{ST}}$ ' suggests that some degree of selfing eventually reduces pollen-mediated gene flow. The effect of selective processes associated with selfing can not be fully disentangled but could also play a role. Selfing and mating between relatives also affect $F_{\mathrm{ST}}$ by increasing inbreeding, which enhances genetic drift. However, other processes can affect inbreeding, in particular inbreeding depression: long-lived species present higher inbreeding depression than short-lived species. Perenniality, and, to a lesser extent, woodiness (which are both surrogates of generation time) appear to have a major influence on plant mating system and inbreeding and hence indirectly on plant genetic structure. These results, together with previous ones showing that generation time affects the rate of molecular evolution $[62,63]$, point to the complex inter-relation between life history traits and plant evolution.

\section{Authors' contributions}

Study design and collection of data were done by RJP and JD. Statistical analyses were performed by JD. Decomposition of population genetic formula $\left(F_{\mathrm{ST}(\delta)}\right)$ was done by
OJH. All three authors have been involved in drafting and revising the manuscript.

\section{Additional material}

\section{Additional file 1}

Plant traits and genetic characteristics of the species. Description of the set of variables studied for the set of species.

Click here for file

[http://www.biomedcentral.com/content/supplementary/1471-

2148-9-177-S1.doc]

\section{Additional file 2}

Phylogenetic supertree of the 263 species. This figure describes the topology of the phylogenetic tree used for PICs analyses.

Click here for file

[http://www.biomedcentral.com/content/supplementary/1471-

2148-9-177-S2.pdf]

\section{Additional file 3}

Mean and standard deviation of $\mathrm{t}_{m}, \mathrm{~F}_{I S}$ and $\mathrm{F}_{S T}$ as a function of the various plant traits. The data provided represent the mean and standard deviation of genetic characteristics of the studied species by plant traits categories (growth form, perenniality, mode of pollen dispersal, mating system).

Click here for file

[http://www.biomedcentral.com/content/supplementary/14712148-9-177-S3.doc]

\section{Additional file 4}

Phylogenetically-controlled regression analyses between $\mathrm{F}_{S T}, \mathrm{~F}_{S T}$ and other variables. The data provided represent the results of the PICs analyses among $\mathrm{F}_{S T}$ and $\mathrm{F}_{S T}$ and other variables for short-lived, long-lived and woody species separately.

Click here for file

[http://www.biomedcentral.com/content/supplementary/14712148-9-177-S4.doc]

\section{Additional file 5}

Mating system distribution (percentage of species) in function of species perenniality, growth form and mode of pollen dispersal. The data provided represent the distribution of the outcrossing rates among all species by perenniality, growth form and mode of pollen dispersal categories. Click here for file

[http://www.biomedcentral.com/content/supplementary/14712148-9-177-S5.doc]

\section{Acknowledgements}

$\mathrm{JD}$ and $\mathrm{OJH}$ are employed by the Belgian Funds for Scientific Research (F.R.S.-FNRS), respectively as Postdoctoral Researcher and Research Associate. JD was also funded by the Gembloux Agricultural University (FUSAGx, Belgium) via the project PPR 10.000. RJP was supported by the EU network of excellence EVOLTREE. The authors thank Pierre-Olivier Cheptou, Myriam Heuertz, Xavier Vekemans, Sylvain Glémin and an anonymous referee for useful comments on a previous version of the manuscript. The authors thank Christopher G Eckert for having kindly provided its database on plants consanguinity index and outcrossing rate. 


\section{References}

I. Lewontin RC: Twenty-five years ago in Genetics: Electrophoresis in the development of evolutionary genetics: milestone or millstone? Genetics 1991, 128:657-662.

2. Hamrick JL, Godt MJW: Effects of life history traits on genetic diversity in plant species. Philosophical Transactions of the Royal Society of London Series B, Biological Sciences 1996, 35 I(I345): | 29|-|298.

3. Hamrick JL, Linhart YB, Mitton JB: Relationships between life history characteristics and electrophoretically detectable genetic variation in plants. Annual Review of Ecology and Systematics 1979, 10:173-200.

4. Nybom H: Comparison of different nuclear DNA markers for estimating intraspecific genetic diversity in plants. Molecular Ecology 2004, I3(5): I |43- I I55.

5. Loveless MD, Hamrick JL: Ecological determinants of genetic structure in plant populations. Annual Review of Ecology and Systematics 1984, I 5:65-95.

6. Duminil J, Fineschi S, Hampe A, Jordano P, Salvini D, Vendramin GG, Petit RJ: Can population genetic structure be predicted from life-history traits? American Naturalist 2007, I 69(5):662-672.

7. Glemin S, Bazin E, Charlesworth D: Impact of mating systems on patterns of sequence polymorphism in flowering plants. Proceedings of the Royal Society B-Biological Sciences 2006, 273( I 604):301 I-3019.

8. Wright S: Evolution and the genetics of populations. Variability within and among natural populations. Volume 4. Chicago: University of Chicago Press; 2006.

9. Crow JF, Aoki KI: Group selection for a polygenic behavioral trait: estimating the degree of population subdivision. Proceedings of the National Academy of Sciences USA 1984, 8 I:6073-6077.

10. Stebbins GL: Self fertilization and population variability in the higher plants. American Naturalist 1957, 9 1:337-354.

II. Holsinger KE: Reproductive system and evolution in vascular plants. Proceedings of the National Academy of Sciences USA 2000, 97(13):7037-7042.

12. Ritland $\mathrm{K}$, Jain S: A model for the estimation of outcrossing rate and gene frequencies using $\boldsymbol{n}$ independent loci. Heredity I98I, 47(I):35-52.

13. Pollak E: On the theory of partially inbreeding finite populations. I. Partial selfing. Genetics 1987, I I 7:353-360.

14. Charlesworth D, Charlesworth B: Inbreeding depression and its evolutionary consequences. Annual Review of Ecology and Systematics 1987, 18:237-268.

15. Hufford KM, Hamrick JL: Viability selection at three early life stages of the tropical tree, Platypodium elegans (Fabaceae, Papilionoideae). Evolution 2003, 57(3):518-526.

16. Fyfe JL, Bailey NTJ: Plant breeding studies in leguminous forage crops. I. Natural cross-breeding in winter beans. J Agric Sci |95I, 41:37|-378.

17. Scofield DG, Schultz ST: Mitosis, stature and evolution of plant mating systems: low-Phi and high-Phi plants. Proceedings of the Royal Society B-Biological Sciences 2006, 273( I 584):275-282.

18. Morgan MT: Consequences of life history for inbreeding depression and mating system evolution in plants. Proceedings of the Royal Society of London Series B-Biological Sciences 2001, 268(1478): | $817-1824$.

19. Husband BC, Schemske DW: Evolution of the magnitude and timing of inbreeding depression in plants. Evolution 1996, 50(I):54-70.

20. Barrett SCH, Harder LD, Worley AC: The comparative biology of pollination and mating in flowering plants. Philosophical Transactions of the Royal Society of London Series B-Biological Sciences | 996, 35 I(1345): | 27|- | 280.

21. Morgan MT, Schoen DJ, Bataillon TM: The evolution of self-fertilization in perennials. American Naturalist 1997, I 50(5):618-638.

22. Goodwillie C, Kalisz S, Eckert CG: The evolutionary enigma of mixed mating systems in plants: Occurrence, theoretical explanations, and empirical evidence. Annual Review of Ecology Evolution and Systematics 2005, 36:47-79.

23. Hardy OJ, Charbonnel N, Freville H, Heuertz M: Microsatellite allele sizes: A simple test to assess their significance on genetic differentiation. Genetics 2003, I63(4): |467-|482.

24. Ronfort JL, Jenczewski E, Bataillon T, Rousset F: Analysis of population structure in autotetraploid species. Genetics I998, I50(2):921-930.
25. Chambers JC, MacMahon JA: A day in the life of a seed: movements and fate of seeds and their implications for natural and managed systems. Annual Review of Ecological Systems 1994, 25:263-292.

26. Stevens PF: Angiosperm Phylogeny Website. Version 8, June 2007. 2007 [http://www.mobot.org/MOBOT/research/APweb/].

27. Beilstein MA, Al-Shehbaz IA, Kellogg EA: Brassicaceae phylogeny and trichome evolution. American Journal of Botany 2006, 93(4):607-619.

28. Bessega C, Vilardi JC, Saidman BO: Genetic relationships among American species of the genus Prosopis (Mimosoideae, Leguminosae) inferred from ITS sequences: evidence for long-distance dispersal. Journal of Biogeography 2006, 33( I I): I 905-1915.

29. Denk T: Phylogeny of Fagus L. (Fagaceae) based on morphological data. Plant Systematics and Evolution 2003, 240: |-4.

30. Eckert AJ, Hall BD: Phylogeny, historical biogeography, and patterns of diversification for Pinus (Pinaceae): Phylogenetic tests of fossil-based hypotheses. Molecular Phylogenetics and Evolution 2006, 40(I): 166-182.

31. Funk VA, Bayer RJ, Keeley S, Chan R, Watson L, Gemeinholzer B, Schilling E, Panero JL, Baldwin BG, Garcia-Jacas N, et al.: Everywhere but Antarctica: Using a supertree to understand the diversity and distribution of the Compositae. Biol Skr 2005 , 55:343-374.

32. Gadek PA, Alpers DL, Heslewood MM, Quinn C]: Relationships within Cupressaceae sensu lato: A combined morphological and molecular approach. American Journal of Botany 2000, 87(7): 1044-1057.

33. Gernandt DS, Lopez GG, Garcia SO, Liston A: Phylogeny and classification of Pinus. Taxon 2005, 54(I):29-42.

34. Ran $\mathrm{HH}$, Wei $X X$, Wang $X Q$ : Molecular phylogeny and biogeography of Picea (Pinaceae): Implications for phylogeographical studies using cytoplasmic haplotypes. Molecular Phylogenetics and Evolution 2006, 4 I (2):405-4I9.

35. Semerikov VL, Zhang HQ, Sun M, Lascoux M: Conflicting phylogenies of Larix (Pinaceae) based on cytoplasmic and nuclear DNA. Molecular Phylogenetics and Evolution 2003, 27(2): I73-I84.

36. Xiang QP, Xiang QY, Liston A, Zhang XC: Phylogenetic relationships in Abies (Pinaceae): evidence from PCR-RFLP of the nuclear ribosomal DNA internal transcribed spacer region. Botanical Journal of the Linnean Society 2004, I45(4):425-435.

37. Dayanandan S, Ashton PS, Williams SM, Primack RB: Phylogeny of the tropical tree family Dipterocarpaceae based on nucleotide sequences of the chloroplast rbc $\mathbf{L}$ gene. American Journal of Botany 1999, 86(8): I | 82-I I90.

38. Doyle JJ, Luckow MA: The rest of the iceberg. Legume diversity and evolution in a phylogenetic context. Plant Physiology 2003, I3 I (3):900-910.

39. Muellner AN, Samuel R, Johnson SA, Cheek M, Pennington TD, Chase MW: Molecular phylogenetics of Meliaceae (Sapindales) based on nuclear and plastid DNA sequences. American Journal of Botany 2003, 90(3):47I-480.

40. Setoguchi H, Kosuge K, Tobe H: Molecular phylogeny of Rhizophoraceae based on rbc I gene sequences. Journal of Plant Research 1999, I I 2( I | 08):443-455.

4I. Wang X-Q, Tank DC, Sang T: Phylogeny and divergence times in Pinaceae: Evidence from three genomes. Mol Biol Evol 2000, I 7(5):773-78|.

42. Weston PH, Barker NG: A new suprageneric classification of the Proteaceae, with an annotated checklist of genera. Telopea 2006, I I(3):3 |4-344

43. Wilson PG, O'Brien MM, Heslewood MM, Quinn C): Relationships within Myrtaceae sensu lato based on a mat $K$ phylogeny. Plant Systematics and Evolution 2005, 25 I (I):3-19.

44. Wojciechowski MF: Reconstructing the phylogeny of legumes (Leguminosae): an early 2 I st century perspective. B. B. Klitgaard and A. Bruneau (eds.), part I0, Higher level systematics. Royal Botanic Garden, Kew. Advances in Legume Systematics 2003:5-35 [http://www.amjbot.org/cgi/content/full/9|/I I//846].

45. Bruneau A, Mercure M, Lewis GP, Herendeen PS: Phylogenetic patterns and diversification in the caesalpinioid legumes. Canadian Journal of Botany 2008, 86(7):697-718.

46. Martins EP, Garland TJ: Phylogenetic analyses of the correlated evolution of continuous characters: a simulation study. Evolution |99|, 45(3):534. 
47. Casgrain $P$, Legendre $P$ : The $\mathbf{R}$ Package for Multivariate and Spatial Analysis, version 4.0 d6 - User's Manual. Département de sciences biologiques, Université de Montréal. 200I [http://www.fas.umontreal.ca/BIOL/legendre/].

48. Felsenstein J: Phylogenie and the comparative method. American Naturalist 1985, 125(I): I-I5.

49. Midford PE, Garland TJ, Maddison WP: PDAP Package of Mesquite. Version I.07. 2005.

50. Maddison WP, Maddison DR: Mesquite: a modular system for evolutionary analysis. Version 2.01. 2007 [http://mesquite project.org].

5I. Martins EP, Diniz-Filho JA, Housworth EA: Adaptive constraints and the phylogenetic comparative method: a computer simulation test. Evolution Int J Org Evolution 2002, 56(I): I-I3.

52. SYSTAT: SYSTAT forWindows. Version 10.2. Statistics. SYS TAT, Evanston, IL. 2002.

53. Ritland K: Inferences about inbreeding depression based on changes of the inbreeding coefficient. Evolution 1990, 44(5): $1230-124 \mid$.

54. Hamrick JL, Godt MJW: Allozyme diversity in plant species. 1989.

55. Wright S: Evolution in Mendelian population. Genetics 1931, 16:97-159.

56. Ingvarsson PK: A metapopulation perspective on genetic diversity and differentiation in partially self-fertilizing plants. Evolution 2002, 56( I 2):2368-2373.

57. Glemin S: Mating systems and the efficacy of selection at the molecular level. Genetics 2007, 177:905-916.

58. Byers DL, Waller DM: Do plant populations purge their genetic load? Effects of population size and mating history on inbreeding depression. Annual Review of Ecology and Systematics 1999, 30:479-513.

59. Wahlund S: Zusammensetzung von Population und Korrelationserscheinung vom Standpunkt der Vererbungslehre aus betrachtet. Hereditas 1928, I I:65-106.

60. Vogler DW, Kalisz S: Sex among the flowers: the distribution of plant mating systems. Evolution 200I, 55(I):202-204.

61. Barrett $\mathrm{SCH}$ : Major evolutionary transitions in flowering plant reproduction: An overview. International Journal of Plant Sciences 2008, I69(I):I-5.

62. Duminil J, Grivet D, Ollier S, Jeandroz S, Petit RJ: Multilevel control of organelle DNA sequence length in plants. Journal of Molecular Evolution 2008, 66:405-4I5.

63. Smith SA, Donoghue MJ: Rates of molecular evolution are linked to life history in flowering plants. Science 2008, 322(5898):86-89.

Publish with Biomed Central and every scientist can read your work free of charge

"BioMed Central will be the most significant development for disseminating the results of biomedical research in our lifetime. "

Sir Paul Nurse, Cancer Research UK

Your research papers will be:

- available free of charge to the entire biomedical community

- peer reviewed and published immediately upon acceptance

- cited in PubMed and archived on PubMed Central

- yours - you keep the copyright
BioMedcentral 